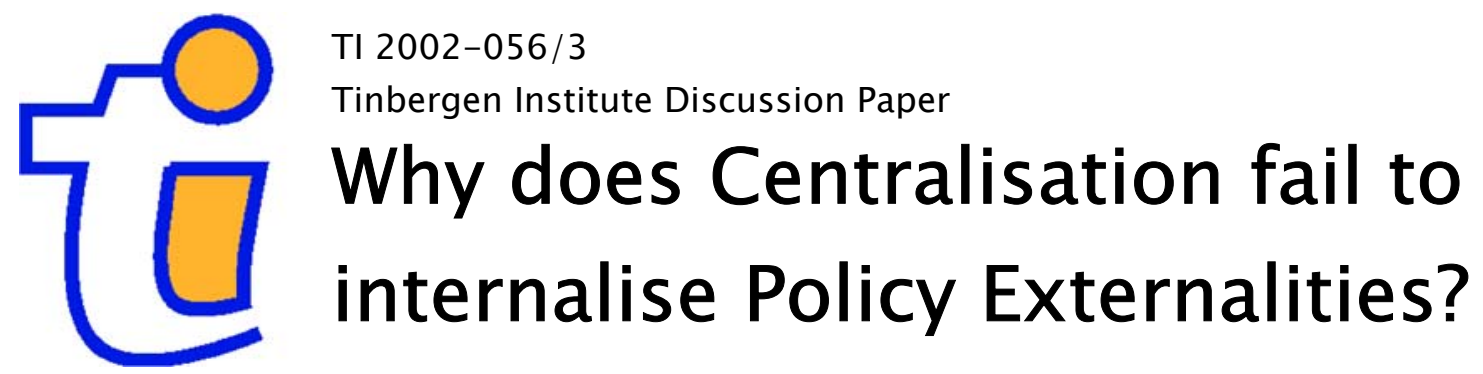

Robert A.J. Durl

Hein J. Roelfsema

' Faculty of Economics, Erasmus University Rotterdam, and Tinbergen Institute,

2 Utrecht School of Economics, Utrecht University. 
Tinbergen Institute

The Tinbergen Institute is the institute for economic research of the Erasmus Universiteit Rotterdam, Universiteit van Amsterdam, and Vrije Universiteit Amsterdam.

Tinbergen Institute Amsterdam

Roetersstraat 31

1018 WB Amsterdam

The Netherlands

Tel.: $\quad+31(0) 205513500$

Fax: $\quad+31(0) 205513555$

Tinbergen Institute Rotterdam

Burg. Oudlaan 50

3062 PA Amsterdam

The Netherlands

Tel.: $\quad+31(0) 104088900$

Fax: $\quad+31(0) 104089031$

Please send questions and/or remarks of nonscientific nature to wdriessen@few.eur.nl.

Most TI discussion papers can be downloaded at http://www.tinbergen.nl. 


\title{
Why Does Centralisation Fail to Internalise Policy Externalities?*
}

\author{
Robert Dur ${ }^{1}$ and Hein Roelfsema ${ }^{2}$ \\ ${ }^{1}$ Tinbergen Institute, Erasmus University Rotterdam \\ ${ }^{2}$ Utrecht School of Economics, Utrecht University
}

\begin{abstract}
We provide an explanation for why centralisation of political decision making results in overspending in some policy domains, whereas too low spending persists in others. We study a model in which delegates from jurisdictions bargain over local public goods provision. If all of the costs of public goods are shared through a common budget, policy makers delegate bargaining to 'public good lovers', resulting in overprovision of public goods. If a sufficiently large part of the costs can not be shared, underprovision persists because policy makers delegate bargaining to 'conservatives'. We derive financing rules that eliminate the incentives for strategic delegation.
\end{abstract}

First draft: May 2002. Revised version: October 2003.

JEL codes: D72, D78, H11, H41.

Keywords: Centralised decision making, strategic delegation, financing rules.

Corresponding author:

Robert Dur

Department of Economics H 7-21

Erasmus University

P.O. Box 1738

3000 DR Rotterdam

The Netherlands

E-mail: dur@few.eur.nl. Fax:+31-10-408 9147

${ }^{*}$ We thank an anonymous referee of this journal, Amihai Glazer, Otto Swank, Huseyin Yildrim, seminar participants in Amsterdam and Rotterdam, and participants of the 2002 Annual Meeting of the Public Choice Society in San Diego, the 2002 Annual Meeting of the European Public Choice Society in Belgirate, and the XIV Villa Mondragone International Economic Seminar in Rome. Dur gratefully acknowledges financial support from NWO, KNAW, and VSNU through a Vernieuwingsimpuls grant. Roelfsema likes to express his appreciation for the hospitality at the Department of Economics of Erasmus University Rotterdam. 


\section{Introduction}

Centralisation of political decision making often fails to produce the desired results. For instance, it is frequently argued that decision making within the European Union results in overspending and overregulation in some policy areas, while too low spending and too little regulation persist in others (see, e.g., Alesina and Wacziarg, 1999, Alesina, Angeloni, and Schuknecht, 2001). Even more puzzling, in policy domains where it is hard to maintain that cooperation among the member states of the EU brings large benefits, integration has progressed impressively. For instance, the externalities on other countries that may not be taken into account under decentralised decision making - the raison d'être of centralisationseem relatively small in regional development policies, agricultural policy, and social funds (Bertola, Jimeno, Marimon and Pissarides, 2001). In contrast, the EU fails to make progress in areas where the coordination of national policies would really help. This holds, for instance, for asylum policies and environmental policies. Why is there such an uneven balance in the results of centralisation of decision making across policy domains?

Studies which try to explain failures of centralised decision making usually rely on noncooperative behaviour of legislators in centralised decision making bodies. For instance, it is well-known that if cost of public goods are financed through a central budget, a common pool problem may arise. At a central level, representatives will push for high spending on public goods which particularly favour their jurisdiction because they only pay a part of the cost of public goods. When central decisions are taken by majority rule, minimum winning coalitions will form. Spending on local public goods in jurisdictions that belong to the coalition will be excessively high at the expense of the jurisdictions outside the coalition. From an ex ante point of view, policy outcomes are Pareto inefficient (see Persson and Tabellini, 2000, chapter 7, for a survey of this literature).

Noncooperative approaches to the behaviour of legislators have been criticised for several reasons. First, when the number of representatives is relatively small (which is the case in, e.g., EU decision making), it is likely that they will exploit the benefits of cooperation. Second, decisions in supranational bodies often require unanimity, thus forcing legislators to cooperate. In the EU, this holds for policies falling under the heading of the second and third pillar.

Recently, Besley and Coate (2003) showed that even if agents in the central decision making body behave cooperatively, suboptimal policy decisions may result. They develop a model in which delegates from jurisdictions bargain over the amounts of public goods provided by the local governments. They show that overprovision of public goods may result from strategic delegation by jurisdictions. In their model, the rationale for centralised decision making is that local public goods have positive spillovers effects on welfare in other regions. Decentralised decision making therefore results in underprovision of public goods. Centralised decision making completely resolves the externality problem provided that local 
policy makers delegate bargaining to agents who have the same preferences for public goods as themselves. However, when the cost of public goods are shared through a common budget, policy makers have an incentive to delegate bargaining to 'public good lovers'. The delegation of a person with strong preferences for public goods serves to increase spending on local public goods at the expense of the common budget. Since in equilibrium all districts send public good lovers, strategic delegation results in overprovision of public goods.

In this paper, we extend the analysis by Besley and Coate (2003) to explain why underprovision of public goods may persist under cooperative centralised decision making. Because our set up is very close to theirs, the two papers may serve as complements to explain why cooperation at a centralised level sometimes results in overspending, whereas in other times it results in underspending. We extend the model by allowing for cost which can not be shared among districts. Examples of policy domains where non-shareable cost are important include environmental policy (which impose indirect costs on local industries), asylum policies (where short term adjustment costs may fall on local communities) and multilateral efforts for peacekeeping (that may result in local casualties). We show that if a sufficiently large part of the cost of public goods can not be shared among regions, underprovision of public goods persists under centralised decision making because local policy makers delegate bargaining to 'conservatives'. Underprovision of public goods is strongest when spillover effects are moderate. We show that both in the absence of spillover effects and in the case of global public goods, centralised decision making produces the socially optimal amounts of public goods. Finally, we derive financing rules that eliminate strategic delegation by local policy makers and thus promote efficient public goods provision.

\section{Related Literature}

A considerable body of literature on federalism shows why centralisation may produce suboptimal policies. Many of the contributions are in the tradition of Oates' (1972) decentralisation theorem. An important assumption in Oates' analysis is that centralisation implies policy uniformity. Then, as Oates shows, the optimal political design of jurisdictions entails a trade-off between the benefits of centralisation of policy making (e.g. economies of scale and internalisation of externalities) and the costs of policy uniformity (a neglect of the diversity in preferences for public goods). In Oates' analysis, policies are set by a social planner. More recently, attention has shifted to the political processes that govern policy choices and the incentives to centralise policy making (Alesina and Spolaore, 1997, Bolton and Roland, 1997, Ellingson, 1998, Alesina, Angeloni, and Etro, 2001a,b, Goyal and Staal, 2002). When policies are set according to the wishes of a majority of voters in the federation, regions which have minority preferences may be worse off under centralised decision making. This may give regions an incentive not to join a federation even when potential efficiency gains 
are large. Recently, Gradstein (2000) argues that a commitment to an egalitarian bargaining rule may be needed to extract the full benefits of centralisation and to guarantee the political sustainability of centralised decision making.

Political-economic studies in the Oates' tradition are well suited to explain the cost of centralisation in policy domains where public goods can not be differentiated according to the preferences of localities. However, in many cases it is possible to decide centrally on geographically differentiated levels of public goods in line with the diverse regional preferences and cultures. This opens up to redistribution games among regions to gather in a larger share of central spending. In Besley and Coate (2003), regions seek to attract a larger share of central spending by delegating bargaining to public good lovers. In Persson and Tabellini (1994) local policy makers use contributions to persuade the central legislator to allocate public spending towards their region. As all regions non-cooperatively make these contributions, in equilibrium the central legislator supplies too many local public goods. Cheikbossian (2000) points out that supply decisions on public goods are often taken at the local level. If these goods are financed through a central budget, voters in each region have an incentive to appoint a public good lover as their local policy maker.

In all these studies, centralisation of political decision making results in overprovision of public goods. The main contribution of our paper is to examine under what conditions underprovision of public goods may persist under centralised cooperative political decision making. Two other recent papers have dealt with this issue (Segendorff, 1998, and Brueckner, 2000). As in our paper, underspending emerges because local policy makers delegate bargaining to conservatives, but for different reasons. Segendorff (1998) assumes that the preferences of the delegates affect policy outcomes even in the case of a breakdown in negotiations. Then, delegating bargaining to a conservative agent serves as a threat to the delegate from the foreign region, and hence changes the bargaining outcome in favour of the domestic policy maker. Brueckner (2000) allows for bargaining over side-payments in addition to policies. He shows that to attract side-payments, local policy makers delegate policy making authority to agents who favour the status quo of low spending on public goods. In contrast to these studies and to the study of Besley and Coate, our paper identifies the characteristics of policy domains in which underspending or overspending is likely to occur.

\section{The Model}

The model revolves around political decision making on public goods provision in two regions. Regions are identical and labelled $i=1,2$. Public goods provision in one region has positive spillover effects on the utility of individuals in the other region. The production of one unit of public goods in a region entails a per capita tax cost of $p$. For convenience, taxes are non-distortionary. In addition, each unit of public goods produced in a region has indirect per capita utility $\operatorname{cost} c$ for all 
citizens in the region. For simplicity, we assume that indirect cost are linear in public goods production. The difference between the tax cost $p$ and the indirect cost $c$ is that tax cost can be shared between the regions through a common central budget while indirect cost can not.

Individuals in each region differ in their preferences for public goods relative to private goods. The utility function of individual $j$ in region $i$ is given by:

$$
U_{i}^{j}=\lambda_{i}^{j}\left[b\left(g_{i}\right)+\kappa b\left(g_{-i}\right)\right]+y-t_{i}-c g_{i}
$$

where $g_{i}$ is the amount of public goods provided in region $i, y$ is gross per capita income, and $t_{i}$ is the per capita tax in region $i{ }^{1}$ Thus, $y-t_{i}$ is per capita consumption of private goods in region $i$. When public goods are financed locally, the per capita tax $t_{i}$ equals $p g_{i}$. When tax cost are shared among the regions through a common budget, $t_{i}=\frac{p}{2}\left(g_{i}+g_{-i}\right)$. In Section 7 , we examine financing through a common budget with more sophisticated sharing rules. As taxes are assumed to be nondistortionary, we will henceforth omit the gross per capita income $y$. The function $b(\cdot)$ is concave and increasing. The parameter $\lambda_{i}^{j} \geq 0$ accounts for differences in preferences for public goods relative to private consumption among individuals in a region. Individuals in each region are symmetrically distributed over the interval $[\underline{\lambda}, \bar{\lambda}]$. The larger is an individual's $\lambda$, the stronger her preference for public goods. The parameter $0 \leq \kappa \leq 1$ measures spillover effects. If $\kappa=0$, spillover effects are absent: individuals in region $i$ do not care for public goods provision in region $-i$. The larger is $\kappa$, the larger is the spillover effect. If $\kappa=1$, individuals care equally for the public goods produced in their own region as they do for the public goods produced in the other region. Then, the public goods may be called 'global' public goods.

The assumption of separability of local public goods in the utility function (1) may be considered restrictive. In the Appendix, we examine an alternative specification where local public goods are strategic substitutes.

\section{The Social Optimum}

Before we consider political decision making on public goods, we first derive the socially optimal amounts of public goods. The social optimum serves as a benchmark against which to evaluate the outcomes of political decision making under different institutional structures. We define the social optimum as the outcome which maximises the unweighted sum of utilities of all individuals in both regions. Since individuals are symmetrically distributed over the interval $[\underline{\lambda}, \bar{\lambda}]$, and with population size normalised to one, social welfare is equal to the sum of the utilities of the median voters in both regions. Hence, the socially

\footnotetext{
${ }^{1}$ Our set up differs slightly from that of Besley and Coate (2003) in the treatment of spillovers. The utility from public goods in their model is $\lambda_{i}^{j}\left[(1-\kappa) \ln g_{i}+\kappa \ln g_{-i}\right]$, implying that the size of spillovers $\kappa$ affects the trade-off between the domestic public good $g_{i}$ and private consumption. This is not the case in our model.
} 
optimal amounts of public goods are found by maximising:

$$
\begin{aligned}
V^{s}= & \lambda_{1}^{m}\left[b\left(g_{1}\right)+\kappa b\left(g_{2}\right)\right]-(p+c) g_{1} \\
& +\lambda_{2}^{m}\left[b\left(g_{2}\right)+\kappa b\left(g_{1}\right)\right]-(p+c) g_{2} \\
= & \lambda^{m}(1+\kappa)\left[b\left(g_{1}\right)+b\left(g_{2}\right)\right]-(p+c)\left(g_{1}+g_{2}\right)
\end{aligned}
$$

where $\lambda_{1}^{m}$ and $\lambda_{2}^{m}$ are the median voter's values of $\lambda$ in region 1 and 2 , respectively, which are the same since regions are identical. Socially optimal public goods provision is described by the following first-order conditions:

$$
\begin{aligned}
& \lambda^{m}(1+\kappa) b^{\prime}\left(g_{1}\right)-p-c=0 \\
& \lambda^{m}(1+\kappa) b^{\prime}\left(g_{2}\right)-p-c=0
\end{aligned}
$$

It is clear from (3) that the socially optimal amounts of $g_{1}$ and $g_{2}$ increase in the intensity of the median voters' preferences for public goods $\lambda^{m}$, increase in spillovers $\kappa$, and decrease in the cost of public goods $(p+c)$.

\section{Decentralised Decision Making}

Under decentralised decision making, each region decides independently on the provision of public goods. Public goods are financed locally. Hence, the per capita tax $t_{i}$ equals $p g_{i}$. We assume that in each region the policy maker's preferences coincide with the preferences of the median voter. ${ }^{2}$ Hence, the policy maker chooses $g_{i}$ to maximise (1) where $\lambda_{i}^{j}=\lambda_{i}^{m}=$ the median $\lambda$ in region $i$. The policy maker in region $i$ takes $g_{-i}$ as given when deciding on $g_{i}$. Optimal public goods provision in each region under decentralised decision making is described by the first-order condition:

$$
\lambda_{i}^{m} b^{\prime}\left(g_{i}\right)-p-c=0
$$

As in the social optimum, public goods provision under decentralised decision making increases in the intensity of the median voter's preferences for public goods and decreases in the costs. In contrast to the social optimum, the amount of public goods is independent of the size of the spillover effect $\kappa$. Comparing (3) with (4), it follows that for $\kappa>0$ decentralised decision making results in underprovision of public goods. The intuition is clear. Since the policy makers do not take into account the positive spillover effect of public goods on the utility of the citizens in the foreign region, the supply of public goods is too low.

\footnotetext{
${ }^{2}$ If local public goods are strategic substitutes, voters have an incentive for strategic delegation, see the Appendix. As a result, underprovision is even more severe than in the case described in the main text.
} 


\section{Centralised Decision Making with Sincere Delegation}

To resolve the problem of underprovision of public goods, the two regions may decide to install a central government or a supra-national decision making body to decide on local public goods provision. We assume that centralised decision making is organised as follows. Each region appoints an agent to the central decision making body. The agents from the two regions bargain over the levels of $g_{1}$ and $g_{2}$. The tax costs of public goods, $p\left(g_{1}+g_{2}\right)$, are financed through a common central budget. Hence, the per capita tax in each region is $t_{i}=$ $\frac{p}{2}\left(g_{i}+g_{-i}\right)$. The indirect costs, $c g_{1}$ and $c g_{2}$, are borne locally.

Assume for the moment that policy makers delegate bargaining at the central level to agents with the same preferences as their own. We refer to this case as 'sincere delegation', as policy makers make no effort to misrepresent local preferences for public goods. Following Besley and Coate (2003), we assume that the bargaining outcome is given by the maximum of the sum of utilities of the agents at the bargaining table: ${ }^{3}$

$$
\begin{aligned}
V^{c}= & \lambda_{1}^{m}\left[b\left(g_{1}\right)+\kappa b\left(g_{2}\right)\right]-\frac{p}{2}\left(g_{1}+g_{2}\right)-c g_{1} \\
& +\lambda_{2}^{m}\left[b\left(g_{2}\right)+\kappa b\left(g_{1}\right)\right]-\frac{p}{2}\left(g_{1}+g_{2}\right)-c g_{2} \\
= & \lambda^{m}(1+\kappa)\left[b\left(g_{1}\right)+b\left(g_{2}\right)\right]-(p+c)\left(g_{1}+g_{2}\right)
\end{aligned}
$$

Notice that $V^{c}$ is identical to the social welfare function $V^{s}$ given by (2). Hence, centralised decision making with sincere delegation produces the socially optimal levels of public goods described by (3). Centralisation of political decision making thus completely resolves the externality problem, provided that delegation is sincere. Recall that the social optimum maximises the sum of the utilities of the median voters in the two regions. Since regions are identical, it follows that both median voters are better off under centralised decision making with sincere delegation compared to decentralised decision making.

\section{Centralised Decision Making with Strategic Delegation}

In this section, we relax the assumption that delegation is sincere. We show that policy makers have an incentive to misrepresent their policy preferences at the central level. As a result, under centralised political decision making underspending may persist or overspending may arise.

To clarify the policy makers' motives for misrepresenting their policy preferences, we first derive the amounts of public goods that would be set if one of the

\footnotetext{
${ }^{3}$ Alternatively, we could assume that the bargaining outcome is described by the Nash bargaining function. This would give policy makers additional incentives to misrepresent their policy preferences, particularly when the preferences of the delegates affect the policy makers' outside options, as in Segendorff (1998), or when delegates also bargain about side-payments, see Brueckner (2000).
} 
policy makers had complete control over central policy. ${ }^{4}$ Given that the direct cost of public goods $p$ are financed through a common budget while indirect cost $c$ are borne locally, the objective function of the policy maker from region $i$ is:

$$
V_{i}^{m}=\lambda_{i}^{m}\left[b\left(g_{i}\right)+\kappa b\left(g_{-i}\right)\right]-\frac{p}{2}\left(g_{i}+g_{-i}\right)-c g_{i}
$$

The optimal levels of $g_{i}$ and $g_{-i}$ are described by:

$$
\begin{aligned}
\lambda_{i}^{m} b^{\prime}\left(g_{i}\right)-\frac{p}{2}-c & =0 \\
\lambda_{i}^{m} \kappa b^{\prime}\left(g_{-i}\right)-\frac{p}{2} & =0
\end{aligned}
$$

Comparing (7) with (3), it is clear that even though centralisation increases both policy makers' welfare, individually optimal provision of public goods generally diverges from the amounts arising under centralised decision making with sincere delegation. This conflict of interest gives policy makers an incentive to distort the central decision. Let us consider two special cases.

First, if indirect costs are zero, $c=0$, all of the costs of public goods are financed through a common budget. Then, unless $\kappa=1$, the supply of domestic public goods $g_{i}$ under centralised decision making is too low from the perspective of the policy maker, while the supply of foreign public goods $g_{-i}$ is too high. This is the common-pool problem: common financing drives a wedge between the benefits and cost of local public goods. While the benefit of an increase in public goods provision in one of the regions is largely region-specific, the cost is spread over the two regions. Common financing therefore gives an incentive to both policy makers to push for a higher supply of domestic public goods and lower supply of foreign public goods. The only exception is when public goods are 'global' public goods, $\kappa=1$. Then, benefits and cost of public goods are perfectly in line given that all cost are shared.

Second, if tax costs are zero, $p=0$, all of the cost are borne locally. Then, unless $\kappa=0$, centralised decision making results in too high a level of domestic public goods and too low a level of foreign public goods from the perspective of each policy maker. Clearly, since all cost are borne locally, the policy maker wants to free ride on an infinite amount of foreign public goods. The policy maker wants to provide only a moderate amount of domestic public goods, viz. the same level that arises under decentralised decision making (compare (7) with (4)). Indirect cost thus give incentives to push for lower domestic public good supply and for higher foreign public good supply. Given that $p=0$, the only case in which a policy maker does not have an incentive to move public goods provision away from the social optimum is when spillovers are absent, $\kappa=0$, i.e. when the supply of public goods under centralised decision making coincides with that under decentralised decision making.

\footnotetext{
${ }^{4}$ This case is close to Besley and Coate (2003)'s analysis of centralised decision making with a noncooperative legislature.
} 
To bring the central decision on public goods provision closer to the policy maker's individual optimum, the policy maker may delegate bargaining at the central level to an agent with preferences different from her own. We assume that policy makers select the agents simultaneously and independently from each other. ${ }^{5}$ Agents are selected from the regions' populations. Recall that individuals in each region differ only in their relative preference for public goods, given by the parameter $\lambda$. We assume that citizens' preferences are sufficiently varied so that an interior solution to the policy maker's selection problem is ensured.

As in the previous section, the bargaining outcome is given by the maximum of the sum of utilities of the agents at the bargaining table:

$$
V^{c}=\lambda_{1}^{d}\left[b\left(g_{1}\right)+\kappa b\left(g_{2}\right)\right]+\lambda_{2}^{d}\left[b\left(g_{2}\right)+\kappa b\left(g_{1}\right)\right]-(p+c)\left(g_{1}+g_{2}\right)
$$

where $\lambda_{i}^{d}$ is the preference parameter of the agent appointed by region $i$ 's policy maker. Maximising (8) to $g_{1}$ and $g_{2}$ results in:

$$
\begin{array}{r}
{\left[\lambda_{1}^{d}+\lambda_{2}^{d} \kappa\right] b^{\prime}\left(g_{1}\right)-p-c=0} \\
{\left[\lambda_{2}^{d}+\lambda_{1}^{d} \kappa\right] b^{\prime}\left(g_{2}\right)-p-c=0}
\end{array}
$$

The comparative statics are obtained by applying the implicit function theorem to $(9)$ :

$$
\begin{aligned}
& \frac{d g_{1}}{d \lambda_{1}^{d}}=\frac{b^{\prime}\left(g_{1}\right)}{-\left[\lambda_{1}^{d}+\lambda_{2}^{d} \kappa\right] b^{\prime \prime}\left(g_{1}\right)}, \frac{d g_{2}}{d \lambda_{1}^{d}}=\frac{\kappa b^{\prime}\left(g_{2}\right)}{-\left[\lambda_{2}^{d}+\lambda_{1}^{d} \kappa\right] b^{\prime \prime}\left(g_{2}\right)}, \\
& \frac{d g_{2}}{d \lambda_{2}^{d}}=\frac{b^{\prime}\left(g_{2}\right)}{-\left[\lambda_{2}^{d}+\lambda_{1}^{d} \kappa\right] b^{\prime \prime}\left(g_{2}\right)}, \text { and } \frac{d g_{1}}{d \lambda_{2}^{d}}=\frac{\kappa b^{\prime}\left(g_{1}\right)}{-\left[\lambda_{2}^{d}+\lambda_{1}^{d} \kappa\right] b^{\prime \prime}\left(g_{1}\right)}
\end{aligned}
$$

which are all positive. Hence, delegating bargaining to an agent with stronger preferences for public goods results in an increase in both the domestic and the foreign public good. The increase in domestic public goods provision is larger than the increase in foreign public goods, unless public goods are global public goods $(\kappa=1)$. It is also clear that the effect of policy maker $i$ 's delegation decision on the bargaining outcome depends on the other policy maker's delegation decision.

Each policy maker selects a delegate $\lambda_{i}^{d}$ so as to maximise $V_{i}^{m}$ given by (6). Since selection takes place simultaneously and independently, each policy maker takes as given the preferences of the delegate from the other region. In the Nash-equilibrium, region 1's policy maker's selection decision is optimal given

\footnotetext{
${ }^{5}$ Clearly, the inefficiencies that arise from strategic delegation may be avoided by coordinating the delegation decision. If both policy makers commit to sincere delegation, the central bargain will produce the social welfare maximising level of local public goods. In practice, however, it seems difficult to commit to such an agreement, as ex ante the preferences of the domestic delegate (and, possibly, even those of the domestic policy maker) are difficult to assess for foreign policy makers.
} 
the selection decision of region 2's policy maker, and vice versa. Equilibrium is described by the following first-order conditions:

$$
\begin{aligned}
& \lambda_{1}^{m}\left[\frac{d g_{1}}{d \lambda_{1}^{d}} b^{\prime}\left(g_{1}\right)+\frac{d g_{2}}{d \lambda_{1}^{d}} \kappa b^{\prime}\left(g_{2}\right)\right]-\left[\frac{d g_{1}}{d \lambda_{1}^{d}}+\frac{d g_{2}}{d \lambda_{1}^{d}}\right] \frac{p}{2}-\frac{d g_{1}}{d \lambda_{1}^{d}} c=0 \\
& \lambda_{2}^{m}\left[\frac{d g_{2}}{d \lambda_{2}^{d}} b^{\prime}\left(g_{2}\right)+\frac{d g_{1}}{d \lambda_{2}^{d}} \kappa b^{\prime}\left(g_{1}\right)\right]-\left[\frac{d g_{2}}{d \lambda_{2}^{d}}+\frac{d g_{1}}{d \lambda_{2}^{d}}\right] \frac{p}{2}-\frac{d g_{2}}{d \lambda_{2}^{d}} c=0
\end{aligned}
$$

Substituting (9) and (10) into (11), and imposing symmetry in equilibrium yields:

$$
\lambda_{i}^{d}=\left[\frac{2\left(1+\kappa^{2}\right)(c+p)}{(1+\kappa)^{2} p+(1+\kappa) 2 c}\right] \lambda_{i}^{m}
$$

Clearly, it is generally not in the policy maker's interest to delegate bargaining to an agent with the same policy preferences as her own $\left(\lambda_{i}^{d}=\lambda_{i}^{m}\right)$. The delegation decision depends crucially on the level of direct and indirect cost and the size of the spillover effect.

As a benchmark, consider the Besley and Coate (2003) case in which all cost are shared among the districts through a common budget $(p>0, c=0)$. Equation (12) then reduces to:

$$
\lambda_{i}^{d}=\left[\frac{2\left(1+\kappa^{2}\right)}{(1+\kappa)^{2}}\right] \lambda_{i}^{m}
$$

The term in large brackets is always greater than one unless $\kappa=1$. Hence, the policy maker has an incentive to delegate bargaining to a 'public good lover'. The reason is a common pool problem. Since all cost of public goods are financed through a common budget, while benefits are - for $\kappa<1$ - at least to some extent region-specific, policy makers have an incentive to push for higher domestic public goods supply and for lower foreign public goods supply. The delegation of a public good lover has two effects. First, it results in an increase in the domestic public goods provision. This raises the utility of the local policy maker. Second, it results in an increase of foreign public goods provision. This lowers the utility of the local policy maker. However, for $\kappa<1$, domestic public goods provision increases by more than foreign public goods provision (see (10)). Starting from the equilibrium with sincere delegation, both policy makers have an incentive to send an agent who cares more for public goods than they do themselves. In the symmetric Nash-equilibrium, both policy makers send a public good lover. As a result, there is overprovision of public goods. This follows from comparing (3) with (9), with $\lambda_{1}^{d}=\lambda_{2}^{d}$ given by (13). Overprovision is largest when $\kappa=0$. Then, $\lambda_{i}^{d}=2 \lambda_{i}^{m}$. The common pool problem is most severe in that case because sending an agent with stronger preferences for public goods does not raise foreign public good supply. The social optimum is immune to strategic delegation only when public goods are global public goods $(\kappa=1)$. As we already argued above, when 
$\kappa=1$ and $c=0$, benefits and cost of public goods are perfectly in line. Hence, there is no incentive to misrepresent policy preferences at the central level.

In the other extreme case, $c>0, p=0$, none of the cost of public goods are shared through a common budget. Equation (12) then reduces to:

$$
\lambda_{i}^{d}=\frac{\left(1+\kappa^{2}\right)}{(1+\kappa)} \lambda_{i}^{m}
$$

Hence, sincere delegation $\left(\lambda_{i}^{d}=\lambda_{i}^{m}\right)$ is optimal only if $\kappa=0$ and $\kappa=1$. When $0<\kappa<1$, the policy maker delegates bargaining to a 'conservative' agent, i.e. someone who cares less for public goods than she does. Starting from $\kappa=0$, optimal 'conservativeness' first increases in $\kappa\left(\frac{d \lambda_{i}^{d}}{d \kappa}<0\right.$ for $\left.0<\kappa<\sqrt{2}-1\right)$ and then decreases in $\kappa\left(\frac{d \lambda_{i}^{d}}{d \kappa}>0\right.$ for $\left.\sqrt{2}-1<\kappa<1\right)$. As we argued above, policy makers have an incentive to move the outcome of centralised decision making away from the social optimum. If all of the cost of domestic public goods are borne domestically, policy makers have an incentive to distort the central decision towards lower domestic public good supply and towards higher foreign public good supply. Intuitively, the externality problem inherent to decentralised decision making persists under centralised decision making. While regions fully bear the cost of domestic public good supply, they only reap a part of the social benefits. The negative gap between local benefits and local cost of domestic public goods increases in the size of the spillover effect $\kappa$. This is the reason why optimal conservativeness increases in $\kappa$ for low values of $\kappa$. When $\kappa$ becomes sufficiently large, an other effect, working in the opposite direction, starts dominating and optimal conservativeness decreases in $\kappa$. This is the effect of conservativeness on foreign public good supply. By delegating bargaining at the central level to a more conservative agent, both domestic and foreign public good supply decrease (see (10)). The decrease in foreign public good supply is a cost to the policy maker because she free rides on foreign public goods provision. This cost is larger, the larger is the spillover effect $\kappa$. In the extreme case of $\kappa=1$, policy makers delegate bargaining to agents with the same preferences as their own, even though each policy maker has an incentive to push for lower domestic public good supply and for higher foreign public good supply. The reason is that sending a more conservative agent reduces domestic and foreign supply by equal amounts when $\kappa=1$; see $(10) .^{6}$

In the general case where both $p>0$ and $c>0$, described by (12), it depends on the magnitude of the cost parameters and the spillover effect whether policy makers have an incentive to delegate bargaining to public good lovers or to conservatives. The larger are indirect cost relative to direct cost, the more conservative are the preferences of the delegates. The effect of the size of spillovers on

\footnotetext{
${ }^{6}$ When local public goods are strategic substitutes, optimal conservativeness increases monotonically in $\kappa$, as sending a more conservative delegate increases foreign public goods supply; see the Appendix.
} 
the delegation decision depends on the relative importance of direct and indirect cost. This is due to the ambiguous effect of $\kappa$ on optimal delegate's preferences in the case $c$ is large, see the discussion above. For various combinations of parameter values, the term in brackets in (12) is one. Hence, policy makers delegate bargaining to agents with the same policy preferences as their own and the social optimum is attained. This is the case if:

$$
\frac{c}{p}=\frac{1-\kappa}{2 \kappa}
$$

If the left hand side of (15) is smaller than the right hand side, policy makers appoint public good lovers, resulting in overspending. If the left hand side of (15) is larger than the right hand side, conservatives are appointed, resulting in underprovision of public goods.

By comparing equation (4) to (9) with $\lambda_{1}^{d}=\lambda_{2}^{d}$ given by (12), we derive the effect of centralisation of decision making on the amounts of public goods. The level of $g_{i}$ is higher under centralised decision making if:

$$
\frac{2\left(1+\kappa^{2}\right)(c+p)}{(1+\kappa) p+2 c}>1 \Leftrightarrow 2 \kappa^{2}(p+c)+(1-\kappa) p>0
$$

which holds unless both $\kappa$ and $p$ are zero. If both $\kappa$ and $p$ are equal to zero, centralisation of decision making does not affect public goods supply because i) there are no externalities to internalise and ii) there is no common pool problem. Depending on the values of $c, p$ and $\kappa$, two types of strategic delegation may occur. In the case of the delegation of public good lovers, both the internalisation of externalities as well as the strategic delegation effect push up the level of public goods as compared to the decentral equilibrium. In the case of the delegation of conservatives, the effects work in opposite directions. The internalisation of externalities pushes up the level of public goods, whereas the strategic delegation mitigates this effect. However, for all $\kappa>0$, the former effect outweighs the latter, thereby increasing the level of public good supply.

Centralisation improves social welfare in each region if the increase in benefits from higher levels of public goods are larger than the increase in costs. Recognise that given symmetry the welfare of each individual median voter is at a maximum at the social optimum. Although each policy maker has an incentive to delegate strategically to alter the distribution of public goods in favour of her region, they do not achieve this goal because both delegate strategically. In equilibrium, welfare in both regions is lower than in the social optimum. To evaluate the effects of centralisation on social welfare in each district, we substitute the levels of public goods arising under centralised and decentralised decision making, respectively, into (2). It follows that centralisation increases social welfare if: 


$$
\lambda_{i}^{m}(1+\kappa)\left[b\left(g_{i}^{c}\right)-b\left(g_{i}^{d}\right)\right]-(p+c)\left(g_{i}^{c}-g_{i}^{d}\right)>0
$$

where the superscript $c$ denotes centralised decisions and $d$ denotes decentralised decisions. Again, there are two cases. If regions delegate bargaining to public goods lovers, the supply of public goods will be higher than the social optimum. As is shown by Besley and Coate (2003), for high levels of $\kappa$ centralisation likely improves welfare. The reason is that the benefits from internalising the externalities are large, whereas the distortion from strategic delegation is small. The opposite is true for low levels of $\kappa$. Therefore, if regions delegate bargaining to public goods lovers, centralisation is only welfare improving in policy domains that have large externalities. If regions delegate bargaining to conservatives, under centralised decision making the supply of public goods is lower than in the social optimum, but higher compared to decentralised decision making. Therefore, even though regions delegate bargaining to conservatives, centralisation improves the welfare of each region.

\section{Optimal Financing Rules}

The previous section showed that when a large part of the total cost of public goods are shared through a common budget, overprovision of public goods results (except for the case $\kappa=1$ ); underprovision occurs when a large part of the cost are borne locally (except for $\kappa=0$ and $\kappa=1$ ). In this section, we derive financing rules that eliminate the incentives for strategic delegation. When underprovision of public goods persists under centralised decision making, an (additional) central subsidy scheme which introduces (or magnifies) a positive budget externality remedies the strategic delegation of conservatives. In the case of overprovision of public goods, an additional central tax scheme restrains the policy makers from delegating public good lovers. ${ }^{7}$

Consider the introduction of a central subsidy $s>0$, or - in case $s<0-$ $\operatorname{tax}$, on $g_{1}$ and $g_{2}$. We assume that the revenues of a tax are fully refunded to the regions and that each region receives half of this fund. In case of a subsidy, each of the regions pays half of the cost of the scheme. The objective function of the delegate of region $i$ is:

$$
U_{i}^{d}=\lambda_{i}^{d}\left[b\left(g_{i}\right)+\kappa b\left(g_{-i}\right)\right]-\frac{p}{2}\left(g_{i}+g_{-i}\right)-c g_{i}+\frac{s}{2}\left(g_{i}-g_{-i}\right)
$$

where the last term is the difference between region $i$ 's subsidy revenues $\left(s g_{i}\right)$ and the region's contribution to the subsidy fund $\left(\frac{s\left(g_{i}+g_{-i}\right)}{2}\right)$.

\footnotetext{
${ }^{7}$ Similarly, one could adjust the share of the tax cost $p$ that is financed through the central budget in order to eliminate strategic delegation. Because we want to allow for the case $p=0$, we introduce an additional tax/subsidy scheme. At the end of this section, we derive which part of the total cost of public goods must be shared so as to guarentee socially optimal public goods supply, using our results for the optimal tax/subsidy scheme.
} 
As in the previous sections, the bargaining outcome is given by the maximum of the sum of the utilities of the delegates. As is clear from (18), this sum is independent of the level of the subsidy $s$. Hence, the subsidy scheme does not affect the outcome of the bargaining by the delegates, given their preferences. The subsidy scheme does, however, affect the policy makers' delegation decisions. The objective function of the policy maker in region $i$ is:

$$
U_{i}^{m}=\lambda_{i}^{m}\left[b\left(g_{i}\right)+\kappa b\left(g_{-i}\right)\right]-\frac{p}{2}\left(g_{i}+g_{-i}\right)-c g_{i}+\frac{s}{2}\left(g_{i}-g_{-i}\right)
$$

Clearly, from the perspective of the policy maker in region $i$, a subsidy (tax) introduces an additional benefit (cost) of units of $g_{i}$ and an additional cost (benefit) of units of $g_{-i}$. Equilibrium is described by the following first-order conditions:

$$
\begin{aligned}
0= & \lambda_{1}^{m}\left[b^{\prime}\left(g_{1}\right) \frac{d g_{1}}{d \lambda_{1}^{d}}+\kappa b^{\prime}\left(g_{2}\right) \frac{d g_{2}}{d \lambda_{1}^{d}}\right]-\left[\frac{d g_{1}}{d \lambda_{1}^{d}}+\frac{d g_{2}}{d \lambda_{1}^{d}}\right] \frac{p}{2}-\frac{d g_{1}}{d \lambda_{1}^{d}} c \\
& +\left[\frac{d g_{1}}{d \lambda_{1}^{d}}-\frac{d g_{2}}{d \lambda_{1}^{d}}\right] \frac{s}{2} \\
0= & \lambda_{2}^{m}\left[b^{\prime}\left(g_{2}\right) \frac{d g_{2}}{d \lambda_{2}^{d}}+\kappa b^{\prime}\left(g_{1}\right) \frac{d g_{1}}{d \lambda_{2}^{d}}\right]-\left[\frac{d g_{2}}{d \lambda_{2}^{d}}+\frac{d g_{1}}{d \lambda_{2}^{d}}\right] \frac{p}{2}-\frac{d g_{2}}{d \lambda_{2}^{d}} c \\
& +\left[\frac{d g_{2}}{d \lambda_{2}^{d}}-\frac{d g_{1}}{d \lambda_{2}^{d}}\right] \frac{s}{2}
\end{aligned}
$$

Substituting (9) and (10) into (20), ${ }^{8}$ and imposing symmetry in equilibrium gives:

$$
\lambda_{i}^{d}=\frac{2\left(1+\kappa^{2}\right)(p+c)}{p(1+\kappa)^{2}+2 c(1+\kappa)-s\left(1-\kappa^{2}\right)} \lambda_{i}^{m}
$$

Clearly, the larger is $s$, the larger is the optimal value of $\lambda_{i}^{d}$. A subsidy creates a positive budget externality from domestic public goods supply. This induces policy makers to delegate bargaining to less conservative agents so as to increase domestic public goods supply. The only exception is when $\kappa=1$. Then, the levels of domestic and foreign public goods are equal, irrespective of the preferences of the delegates (see equation (9)). Hence, in that case, the tax/subsidy scheme does not affect the budgets of the local governments and, hence, the delegation decision.

Denote $s^{*}$ as the optimal subsidy, that is, the subsidy that results in sincere delegation by both policy makers $\left(\lambda_{i}^{d}=\lambda_{i}^{m}\right)$. The optimal subsidy (tax) is:

$$
s^{*}=-\frac{p(1-\kappa)-2 c \kappa}{1+\kappa}
$$

\footnotetext{
${ }^{8}$ Recall that the bargaining outcome is independent of the tax/subsidy scheme. Hence, we can use (9) and (10) to simplify (20).
} 
for any $\kappa \neq 1 .{ }^{9}$ The optimal subsidy increases in $c$ and $\kappa$ and decreases in $p$.

To evaluate the properties of $s^{*}$, consider the situation where all costs of public goods are financed through a common budget $(p>0, c=0)$. In this case, $(22)$ reduces to:

$$
s^{*}=-\frac{p(1-\kappa)}{(1+\kappa)} \leq 0
$$

Hence, in the absence of indirect cost and with $\kappa \neq 1$, a central tax $\left(s^{*}<0\right)$ is needed to eliminate the strategic delegation of public good lovers. The optimal tax decreases in the level of spillovers. When spillovers are absent, the optimal tax $\left(s^{*}=-p\right)$ implies that none of the cost of public goods are actually shared. Centralised decision making with an optimal subsidy then results in the same public goods supply as under decentralised decision making, which is socially optimal in the absence of spillover effects. Common financing of all cost $\left(s^{*}=0\right)$ is only optimal in case of global public goods $(\kappa=1)$.

In the other extreme case where all of the cost of public goods are borne domestically $(c>0, p=0)$, (22) equals:

$$
s^{*}=\frac{2 c \kappa}{1+\kappa} \geq 0
$$

Hence, for $\kappa>0$, a subsidy is needed to induce policy makers to refrain from delegating bargaining to a conservative agent. The subsidy increases in the size of spillovers. This may come as a surprise since, starting from $\kappa=0$, optimal conservativeness of the delegate first increases in $\kappa$ and, from $\kappa=\sqrt{2}-1$, decreases in $\kappa$ (see Section 7). The reason is that the effectiveness of the subsidy in changing the policy makers' delegation decision reduces in $\kappa$. When $\kappa$ is small, sending a less conservative agent has a relatively large effect on the supply of the domestic public good and a relatively small effect on the supply of the foreign public good. The net additional receipts from the subsidy scheme are therefore large when $\kappa$ is low. When $\kappa$ approaches unity, sending a less conservative agent increases domestic and foreign public good supply by almost the same amount, rendering the subsidy scheme close to budgetary neutral for each region. Hence, a large subsidy per unit of public good is needed to offset a small distortion in the policy maker's delegation decision. When local public goods closely resemble global public goods, the optimal subsidy approaches the total cost of public good supply $\left(s^{*} \rightarrow c\right)$. Hence, as for the case $p>0, c=0$, we conclude that sharing all of the cost of public goods through a central budget is only optimal in case of global public goods.

\footnotetext{
${ }^{9}$ Obviously, there does not exist an optimal level of $s$ for $\kappa=1$ because the tax/subsidy scheme does not affect the delegation decision in that case. This is of no concern because delegation is always sincere if $\kappa=1$, see equation (12) in the previous section.
} 
Using (22), we can derive which part of the total cost of public goods must be shared to guarantee socially optimal public good supply:

$$
\frac{\left(p+s^{*}\right) g_{i}}{(p+c) g_{i}}=\frac{2 \kappa}{1+\kappa}
$$

Hence, sharing none of the cost is optimal only in the absence of spillovers, while common financing of all cost is only optimal in case of global public goods.

The optimum financing rule described by (25) may not only be socially optimal, but also politically feasible. When deciding on the financing rule, local policy makers recognise that equal amounts of public goods result for each region. ${ }^{10}$ They also recognise that over- or underspending emerges when financing differs from the optimal financing rule. The policy makers will therefore decide to implement the optimum financing rule. ${ }^{11}$

Sharing only a part of the cost of policies decided on at central level is widely observed in practice. For instance, EU grants for local projects out of the Regional Development Fund have to be matched by equal grants from national governments, the so-called co-financing system. As DelRossi and Inman (1999) show in an empirical study on US legislators' demand for local public goods, co-financing significantly reduces the legislators' demand for centrally financed projects. Bonuses to compensate for local indirect costs are less frequently observed. One reason may be that non-shareable costs are difficult to quantify $e x$ ante and are probably hard to verify ex post. Hence, it may be politically difficult to agree on them before decision making on the amounts of public goods starts.

\section{Concluding Remarks}

This paper provided an explanation for why in some policy domains cooperative centralised decision making on local public goods leads to overspending, whereas in other areas public spending on local public goods is too low. We argued that if costs of local public goods are shared among participating regions through a common budget, the delegation of public goods lovers leads to oversupply. If a sufficiently large part of the costs are non-shareable, the delegation of conservatives results in underspending. Lastly, we derived cost sharing rules which eliminate the incentives to delegate bargaining at the central level to agents with preferences different from the domestic policy maker's preferences.

\footnotetext{
${ }^{10}$ This will not be the case when the median voters in the regions differ in their preferences for public goods. Then, policy makers will try to manipulate decision making on the financing rule in order to bring the central decision closer to their preferences.

${ }^{11}$ Introducing separation of powers in the budgetary process may also contribute to efficient provision of public goods. Chari et al. (1997) build a model where voters in each state delegate spending-prone agents to Congress, but appoint a fiscally conservative President so as to curtail excessive spending. In a model that mirrors decision making in the EU, Mazza and Van Winden (2002) show that separation of powers, where the budget is set before the policy selection stage, reduces the incentives to lobby for local public goods and therefore the size of spending at a central level.
} 
Our analysis can be extended in several important ways. One is to incorporate checks and balances. Chari et al. (1997) examine the role of a president as a check on overspending. They allow for 'split ticket' voting on the preferences of the delegates and the president. In the constitutional debate in the European Union, it is still an open issue whether institutional reform should move towards an elected head of the European Commission, who may serve as a check on the members of the Commission delegated by the member countries.

A second extension is to allow for interregional heterogeneity in preferences and/or differences in local costs of public goods. Differences in non-shareable costs across regions may add to our understanding of why it is so difficult to agree on common policies. For instance, the reluctance of the US to sign the Kyoto protocol may have more to do with the relatively high costs for growing US industries to comply with restrictive global emission standards, than with weak preferences of the US electorate for environmental protection.

Another interesting extension of the model would be to allow for more than two countries. This seems especially relevant in the light of the enlargement process in the EU. Member states that benefit heavily from policies that are commonly financed fear that enlargement may erode their privileged position, and reduce the possibility of deepening cooperation. Further, countries that have strong preferences for environmental protection fear that enlargement may lower the common standards in this domain. Therefore, enlargement may change the attitudes of local policy makers towards policy making in Brussels and may influence their delegation decision.

Our analysis has shed light on problems that arise with 'cooperative policy coordination', a phenomenon that has become more important over time. Increased interdependence creates incentives for policy coordination at a regional and global level, for instance in the case of environmental degradation or coping with large numbers of refugees. On most of these issues, policy makers cooperate in the international arena through policy coordination, not through cost sharing. Our model seems to be well placed to explain the inefficiencies that may arise in political decision making when countries decide to cooperate, but do not share.

\section{References}

Alesina A., I. Angeloni and L. Schuknecht (2001).What Does the European Union Do?, Cambridge, MA, NBER Working Paper 8647.

Alesina A., I. Angeloni and F. Etro (2001a). Institutional Rules for Federations, Cambridge, MA, NBER Working Paper 8646.

Alesina A., I. Angeloni and F. Etro (2001b). The Political Economy of International Unions, Cambridge, MA, NBER Working Paper 8645.

Alesina, A. and E. Spolaore (1997). On the Number and Size of Nations, Quarterly Journal of Economics 112(4): 1027-1056.

Alesina, A. and R. Wacziarg (1999). Is Europe Going too Far?, Carnegie- 
Rochester Conference Series On Public Policy 51(1): 1-42.

Bertola, G., J.F. Jimeno, R. Marimon and C. Pissarides (2001). EU Welfare Systems and Labor Markets: Diverse in the Past, Integrated in the Future?, in G. Bertola, T. Boeri and G. Nicoletti (eds.). Welfare and Employment in a United Europe, Cambridge, MA: MIT Press.

Besley, T. and S. Coate (2003). Centralized versus Decentralized Provision of Local Public Goods: A Political Economy Approach, Journal of Public Economics 87(12): 2611-2637.

Bolton, P. and G. Roland (1997). The Breakup of Nations: A Political Economy Analysis, Quarterly Journal of Economics 112(4): 1057-1090.

Brueckner, M. (2000). Unanimity versus Consensus Bargaining: Strategic Delegation and Social Optimality, Mimeo, ZEI, Bonn.

Chari, V.V., L.E. Jones and R.Marimon (1997). The Economics of SplitTicket Voting in Representative Democracies, American Economic Review 87(5): 957-976.

Cheikbossian, G. (2000). Federalism, Distributive Politics and Representative Democracy, Economics of Governance 2(1): 105-122.

DelRossi, A. F. and R. P. Inman (1999). Changing the Price of Pork: The Impact of Local Cost Sharing on Legislators' Demands for Distributive Public Goods, Journal of Public Economics 71(2): 247-273.

Ellingsen, T. (1998). Externalities vs. Internalities: A Model of Political Integration, Journal of Public Economics 68(2): 251-268.

Goyal, S. and K. Staal (2002). The Political Economy of Regionalism, European Economic Review, forthcoming.

Gradstein, M. (2000). The Political Economy of Sustainable Federations, CESifo, Working Paper Series No. 315.

Mazza, I. and F. van Winden (2002). Does Centralization Increase the Size of Government? The Effects of Separation of Powers and Lobbying, International Tax and Public Finance 9 (4): 379-389.

Oates, W. E. (1972). Fiscal Federalism. New York, Harcourt Brace Jovanovich.

Persson, T. and G. Tabellini (1994). Does Centralization Increase the Size of Government?, European Economic Review 38(3-4): 765-73.

Persson, T. and G. Tabellini (2000). Political Economics: Explaining Economic Policy, Cambridge, MA, MIT Press.

Segendorff, B. (1998). Delegation of Bargaining and Power, Stockholm School of Economics, Working Paper Series in Economics and Finance No. 248. 


\section{Appendix}

This Appendix studies the case where local public goods are strategic substitutes. Using the same notation as in the main text, the utility function is given by:

$$
U_{i}^{j}=\lambda_{i}^{j} b\left(g_{i}+\kappa g_{-i}\right)+y-t_{i}-c g_{i}
$$

The Social Optimum. Socially optimal public goods provision is described by:

$$
\begin{aligned}
& \lambda^{m} b^{\prime}\left(g_{1}+\kappa g_{2}\right)+\kappa \lambda^{m} b^{\prime}\left(g_{2}+\kappa g_{1}\right)-p-c=0 \\
& \lambda^{m} b^{\prime}\left(g_{2}+\kappa g_{1}\right)+\kappa \lambda^{m} b^{\prime}\left(g_{1}+\kappa g_{2}\right)-p-c=0
\end{aligned}
$$

Decentralised Decision Making. When local public goods are strategic substitutes, voters have an incentive to delegate policy making to an agent with preferences different from their own. Given $g_{-i}$, policy maker $i$ 's optimal public good supply is described by:

$$
\lambda_{i}^{p} b^{\prime}\left(g_{i}+\kappa g_{-i}\right)-p-c=0
$$

where $\lambda_{i}^{p}$ denotes the preferences of the policy maker in region $i$. Given the preferences of the policy maker in region $-i$, the median voter's optimal preferences of the policy maker in region $i$ are described by:

$$
\frac{\partial U_{i}^{m}}{\partial \lambda_{i}^{p}}=\lambda_{i}^{m}\left[\frac{d g_{i}}{d \lambda_{i}^{p}} b^{\prime}\left(g_{i}+\kappa g_{-i}\right)+\frac{d g_{-i}}{d \lambda_{i}^{p}} \kappa b^{\prime}\left(g_{i}+\kappa g_{-i}\right)\right]-\frac{d g_{i}}{d \lambda_{i}^{p}}(p+c)=0
$$

where, using (A3):

$$
\begin{aligned}
\frac{d g_{i}}{d \lambda_{i}^{p}} & =\frac{b^{\prime}\left(g_{i}+\kappa g_{-i}\right)}{-\lambda_{i}^{p}\left(1-\kappa^{2}\right) b^{\prime \prime}\left(g_{i}+\kappa g_{-i}\right)}>0 \\
\frac{d g_{-i}}{d \lambda_{i}^{p}} & =-\kappa \frac{d g_{i}}{d \lambda_{i}^{p}}<0
\end{aligned}
$$

Delegating policy making to an agent with stronger preferences for public goods increases domestic public goods supply, but reduces public goods supply in the foreign region. Substituting (A5) in (A4), and using (A3) to simplify, results in:

$$
\lambda_{i}^{p}=\left(1-\kappa^{2}\right) \lambda_{i}^{m}
$$

For any $\kappa>0$, the median voter delegates policy making to someone who cares less for public goods than she does. The reason is clear. Given the preferences of the foreign policy maker, delegating to a more conservative agent implies less domestic public goods, but this is partly compensated for by higher foreign public goods supply. If local public goods are near perfect substitutes $(\kappa$ approaches 1 ), a reduction in $g_{i}$ is almost completely compensated for by an increase in $g_{-i}$, resulting in delegation to an extremely conservative policy maker. Clearly, 
underprovision of public goods is more severe than in the case described in the main text as, in addition to the externality problem, voters appoint conservative policy makers when local public goods are strategic substitutes.

Centralised Decision Making. Public goods provision resulting from the bargain between the delegates from the two countries is described by:

$$
\lambda_{i}^{d} b^{\prime}\left(g_{i}+\kappa g_{-i}\right)+\kappa \lambda_{-i}^{d} b^{\prime}\left(g_{-i}+\kappa g_{i}\right)-p-c=0
$$

Given the preferences of the foreign delegate, optimal preferences of the domestic delegate are given by:

$$
\frac{\partial U_{i}^{m}}{\partial \lambda_{i}^{d}}=\lambda_{i}^{m}\left[\frac{d g_{i}}{d \lambda_{i}^{d}} b^{\prime}\left(g_{i}+\kappa g_{-i}\right)+\frac{d g_{-i}}{d \lambda_{i}^{d}} \kappa b^{\prime}\left(g_{i}+\kappa g_{-i}\right)\right]-\frac{d g_{i}}{d \lambda_{i}^{d}}\left(\frac{p}{2}+c\right)-\frac{d g_{-i}}{d \lambda_{i}^{d}} \frac{p}{2}=0
$$

Using (A7) to find the values of $\frac{d g_{i}}{d \lambda_{i}^{d}}$ and $\frac{d g_{-i}}{d \lambda_{i}^{d}}$, and imposing symmetry in equilibrium, we obtain:

$$
\lambda_{i}^{d}=\frac{2\left(1-\kappa^{2}\right)(c+p)}{\left(1-\kappa^{2}\right) p+(1+\kappa) 2 c} \lambda_{i}^{m}
$$

As in the main text, we find that the policy maker delegates bargaining to a public good lover when $c=0$, while she delegates bargaining to a conservative when $p=0$. If all of the cost are shared $(c=0)$, then $\lambda_{i}^{d}=2 \lambda_{i}^{m}$ for all $\kappa<1$. The intuition is clear. Compared to the bargaining outcome with sincere delegation, each policy maker desires higher domestic public goods supply and lower foreign public goods supply. Given the preferences of the other delegate, delegating to an agent with $\lambda_{i}^{d}=2 \lambda_{i}^{m}$ increases $g_{i}$ up to the policy maker's optimal level (a delegate with $\lambda_{i}^{d}>2 \lambda_{i}^{m}$ would oversupply $g_{i}$ even if all costs are shared) and reduces the level of $g_{-i}$. Hence, by delegating to an 'extreme lover' of public goods, the policy maker kills two birds with one stone. This is in contrast to the case in the main text, where delegating to a public good lover increases foreign public good supply as well.

If the cost of public goods provision are non-shareable $(p=0)$, for all $\kappa>0$ there is conservative delegation, as in the main text. However, in contrast to the results in the main text, optimal conservativeness increases monotonically in $\kappa$. The intuition is that when public goods are strategic substitutes, sending a more conservative delegate increases the level of $g_{-i}$. In the limiting case where $\kappa$ approaches 1 , policy makers delegate bargaining to agents who do not care for public goods at all, so as to 'force' a large increase in public goods provision in the other region. Since both policy makers do, no public goods are supplied, as under decentralised decision making, see (A6). 